\title{
POSSÍVEIS IMPACTOS DE FAKE NEWS NA PERCEPÇÃO-AÇÃO COLETIVA ${ }^{1}$
}

\section{Juliana Moroni}

\begin{abstract}
Doutora em Filosofia pela Universidade Estadual do Rio de Janeiro (UERJ). Mestre em Filosofia pela Universidade Estadual Paulista (UNESP/Marília). Possui graduação, bacharelado e licenciatura plena, em Filosofia pela Universidade Estadual Paulista (UNESP/Marília). E-mail: julianamoroni@yahoo.com.br
\end{abstract}

\section{RESUMO}

O objetivo deste trabalho é investigar a relação entre fake news ${ }^{2}$, padrões informacionais e percepção-ação coletiva, a partir do paradigma da complexidade. Nesse sentido, analisamos, neste trabalho, o seguinte problema: Qual a influência da disseminação de fake news, disponíveis nos meios digitais, na percepção-ação coletiva? Argumentamos em defesa de que as hipóteses do paradigma da complexidade oferecem subsídios teóricos inovadores para a análise de temas e de problemas sobre a relação entre fake news e percepção-ação coletiva. Nosso desafio será fornecer subsídios para o pressuposto de que fake news, disponíveis nos meios digitais, proporcionam a emergência de padrões informacionais coletivos que podem alterar hábitos sociais bem estabelecidos. Nosso pressuposto principal é o de que essas alterações ocorrem devido à influência negativa da manipulação de informação através de fake news nas propriedades de prospectividade, flexibilidade e coordenação emergente relativas à percepção-ação humana.

PALAVRAS-CHAVE: Fake News. Percepção-ação Coletiva. Informação. Paradigma da Complexidade. Padrão informacional.

\section{POSSIBLE FAKE NEWS IMPACTS ON COLLECTIVE PERCEPTION-ACTION}

\begin{abstract}
The objective of this work is to investigate the relationship between fake news, informational patterns and collective perception-action, from the complexity paradigm. In this sense, we analyze, in this work, the following problem: What is the influence of spreading fake news, available on digital media, on collective perception-action? We argue that the hypotheses of the paradigm of complexity offer innovative theoretical subsidies for the analysis of themes and problems about the relationship between fake news and collective perception-action. The challenge of our research will be to provide support for the assumption that fake news, available on digital media, provides the emergence of collective information patterns that can change well-established social habits. Our main
\end{abstract}


assumption is that these changes occur because of the negative influence of information manipulation through fake news on the properties of flexibility and emergent coordination relative to human perception-action

KEYWORDS: Fake News. Collective Perception-action. Information. Complexity Paradigm.

\section{INTRODUÇÃO}

A Era da conectividade propicia, através do uso de tecnologias digitais, o registro e a análise de um enorme conjunto de dados denominados Big Data. Cliques e postagens em redes sociais como WhatsApp, Instagram, Facebook, Twitter e Youtube, envio e recebimento de $e$ mails, uso de cartões magnéticos em roletas de metrôs, postagens em blogs, compras e transações bancárias via internet, preenchimentos de formulários, utilização de urnas eletrônicas em época de eleições, entre outros liberam de forma gratuita dados de milhares de pessoas no mundo. Através das "pegadas digitais" deixadas pelos usuários de tecnologias conectadas, Governos, instituições públicas ou empresas privadas têm acesso a informações pessoais que podem ser usadas para a manipulação da opinião pública e da percepção-ação coletiva. Entre os usos dessas informações estão o direcionamento de anúncios comerciais e propagandas políticas para grupos específicos de usuários, bem como a propagação de fake news.

A proposta deste texto é investigar a relação entre fake news, padrões informacionais e percepção-ação coletiva, a partir do paradigma da complexidade. Nesse sentido, analisamos o problema norteador deste trabalho: Qual a influência da disseminação de fake news, disponíveis nos meios digitais, na percepção-ação coletiva?

Amparado no paradigma da complexidade, este texto tem como desafio oferecer contribuições à hipótese de que fake news, disponíveis nos meios digitais, proporcionam a emergência de padrões informacionais coletivos que podem alterar hábitos sociais bem estabelecidos, os quais constituem nichos ecológicos humanos. Nossa hipótese central é a de que essas modificações ocorrem devido à influência negativa da manipulação de informação, através de fake news, nas propriedades de prospectividade (propriedade antecipatória da ação), flexibilidade (propriedade que permite a habilidade para encerrar uma ação em contextos que se mostram adversos) e coordenação emergente (propriedade que possibilita a ação sincronizada entre indivíduos, os quais podem agir de modo simulado ou involuntário) relativas à percepçãoação humana.

Considerando o problema a ser investigado e a hipótese principal deste trabalho, 
inicialmente expomos a relação entre os Big Data e a disseminação de fake news. Posteriormente conjecturamos, a partir do paradigma da complexidade, a influência da disseminação de fake news na percepção-ação coletiva, mais especificamente nas propriedades de prospectividade, flexibilidade e coordenação emergente. Concluímos este trabalho considerando possíveis impactos de fake news na ação coletiva humana, através da percepção de affordances.

\section{BIG DATA: MANIPULAÇÃO E DISSEMINAÇÃO DE FAKE NEWS}

“Dados são uma forma de poder.” (ILIADIS; RUSSO, p. 1, 2016, tradução nossa). ${ }^{3}$

A disseminação e manipulação de fake news têm como suporte principal a coleta de dados de usuários de tecnologias digitais. A disseminação e manipulação de dados são feitas através do manuseamento e controle de frações de informações que constituem os Big Data. A utilização dos Big Data pode ser percebida no âmbito que envolve a saúde pública, a política, no ambiente econômico dos negócios, nas interações sociais de lazer e em centenas de outros contextos em que há trocas de informações no ambiente digital.

Inicialmente, os Big Data foram caracterizados como volume ou quantidade de informação tão ampla que não se encaixava mais na memória que os computadores usavam para processamento. Relacionados às previsões, os Big Data são utilizados na matemática e na estatística, áreas de estudo que utilizam grande quantidade de dados para estipular probabilidades. (MAYER-SCHÖNBERGER; CUKIER, 2013). Ainda que atualmente não exista um consenso sobre o conceito de Big Data, muitas propriedades são reconhecidas na sua caracterização: volume, velocidade, variedade, veracidade, validade, valor, variabilidade, local, vocabulário e imprecisão. (JAIN; GYANCHANDANI; KHARE, 2016).

Os Big data são fonte de informações sobre os usuários de tecnologias digitais, os quais tem aspectos de suas vidas particulares revelados e vendidos à empresas privadas como o Facebook ou à instituições governamentais. Entre algumas das informações acessadas por empresas como Facebook estão: nome, sexo, orientação sexual, idade, profissão, perspectivas políticas, preferências culturais, religião, nível educacional, localidade, gênero, tipo sanguíneo, etc.

O Facebook se tornou um exemplo claro de como ocorre à manipulação de dados individuais para diversas finalidades, desde a venda de produtos aos usuários da rede social até a influência no sistema político e nas eleições de países nos quais a plataforma tem grande 
aceitação. Um exemplo dessa manipulação foi o vazamento de dados de usuários do Facebook, sem prévia autorização, para que a empresa britânica Cambridge Analytica coletasse informações de mais de 50 milhões de usuários da rede social, principalmente aqueles residentes nos EUA. A Cambridge Analytica trabalhou para Donald Trump nas eleições americanas de 2016, usando informações de usuários do Facebook para influenciar nas suas escolhas e decisões políticas, através de mensagens personalizadas.

Após a repercussão do uso de dados de usuários do Facebook pela empresa Cambridge Analytica, medidas para a proteção de dados ganharam força e estão sendo implantadas em diversos países com o objetivo de proteger informações de privacidade dos usuários. Exemplos dessas medidas são: a aprovação do "Regulamento geral de proteção de dados na União Europeia ou RGPD”, o qual permite aos usuários da internet maior controle sobre o consentimento da coleta e do uso dos seus dados por empresas e provedores em troca de serviços oferecidos. (RONCOLATO, 2018). ${ }^{4}$ Além dos países da União Europeia, foi aprovado recentemente pelos congressistas brasileiros. ${ }^{5}$ o projeto de lei que prevê multa de até 50 milhões de reais para empresas privadas ou órgãos relacionados ao poder público que descumprirem as medidas de proteção de dados. (VILELA, 2018). ${ }^{6}$ De acordo com Valente (2018), a "Lei geral de proteção de dados" foi sancionada por Michel Temer, mas ainda aguardará um período de 18 meses para entrar em vigor, a contar da data da sanção da lei, ocorrida em 14 de agosto de 2018. A lei de proteção de dados brasileira garantirá a realização de negócios entre empresas brasileiras e estrangeiras. Segundo Valente $(2018)^{7}$, além de acordos comerciais, alguns pontos que a lei brasileira também faz menção são:

1 - O acesso de usuários aos seus dados individuais, retidos pelas plataformas de mídias sociais. 2 - O direito de autorizar ou proibir a coleta de dados realizada por empresas, bem como ser informado sobre a finalidade do uso desses dados.

3 - O direito dos pacientes de não terem seus registros médicos comercializados.

4 - O direito a um patamar de proteção mais elevado relacionado aos dados que indiquem posicionamentos políticos, etnias, sexualidades, crenças religiosas, registros de saúde, etc.

Se por um lado, os Big Data podem ser usados para manipular ações individuais e coletivas com finalidades econômicas e políticas, por outro lado, o armazenamento e o manejo da informação que constitui os Big Data pode ser positivo por contribuir, por exemplo, para o desenvolvimento de pesquisas científicas em diversas áreas do conhecimento, visando o bem comum, ou ainda na representatividade e no empoderamento de minorias políticas, através da 
utilização de plataformas digitais.

Exemplos da contribuição positiva da utilização dos Big Data podem ser observadas:

1- Na ciência, através de previsão e de diagnóstico de doenças ou nas investigações no campo da astronomia.

2 - No empoderamento e representatividade de minorias políticas através de denúncias de violações de direitos humanos, de violência contra mulheres, LGBTTIs, denúncias de racismo, entre outros por meio de fóruns de debates, redes sociais ou outros tipos de serviços oferecidos por plataformas digitais que proporcionam a divulgação de conteúdos através de compartilhamentos de textos, fotos e vídeos.

Já em relação ao aspecto negativo do uso dos Big Data, temos como exemplos:

1- A manipulação comercial de monetização e venda de dados de usuários de mídias sociais, sem a prévia permissão destes, para empresas privadas a fim de que essas empresas possam vender seus produtos.

2 - Casos de manipulação de dados com objetivos políticos, como a propagação de fake news em campanhas eleitorais e em sistemas políticos, prejudicando a estabilidade de sistemas de governos democráticos.

3 - A influência negativa dos Big Data na maneira negativa e perniciosa nas quais fake news vem direcionando ações humanas, tais como: agressões e mortes de pessoas que tiveram suas vidas expostas nas redes sociais de modo fraudulento.

O acesso aos Big Data e a forma de lidar com as suas propriedades (volume, velocidade, variedade, veracidade, validade, valor, variabilidade, local, vocabulário e imprecisão) é realizada pelas tecnologias de Big Data, as quais, segundo a Intel (201, p. 4), proporcionam mais eficiência na coleta, armazenamento e análise de dados volumosos, variados e gerados mais rapidamente em comparação com estruturas e ferramentas tradicionais. ${ }^{8}$ Entre as tecnologias de Big Data estão softwares e hardwares capazes, por exemplo, de minerar dados, de auxiliar, a partir de dados, em previsões de eventos e na tomada de decisões. Exemplos de tecnologias de Big Data são: Data Mining (usado na mineração de dados), Predictive analytics (permite descobrir, avaliar e otimizar modelos preditivos a partir dos Big data), NoSQL databases (bancos de dados de valores-chave, documentos e gráficos), Search and knowledge discovery (ferramentas que permitem a extração de informações a partir de grandes repositórios de dados estruturados e não estruturados vindos de diversas fontes como sistemas de arquivos, aplicativos, etc), In-memory data fabric (permite o processamento de grandes quantidades de 
dados através da memória de um sistema de computador distribuído), Stream analytics (software que pode filtrar, integrar e analisar enormes quantidades de transferências de dados advindos de múltiplas fontes e em diferentes formatos) ${ }^{9}$, etc. (PRESS, 2016). ${ }^{10}$

Em relação aos aspectos positivos da utilização dos Big Data, como exemplificamos, na previsão e diagnóstico de doenças, temos que: o uso dos Big Data é realizado em hospitais, laboratórios, centros de pesquisas que, através do cruzamento de dados de pacientes, ampliam a possibilidade de monitoramento da saúde dos enfermos. (COSTA; SILVA; MURAROLLI, 2017). De acordo com Costa, Silva e Murarolli (2017, p. 13-17), entre as diversas aplicações dos Big Data na área da saúde estão às contribuições para:

1- O tratamento do câncer: pesquisadores da Universidade de Boston, nos EUA, utilizam, de forma mais rápida e abrangente, bancos de dados para cruzar informações de pacientes de diversos países a fim de descobrir melhores formas de tratamentos da doença.

2 - Nos estudos sobre uma vacina para o HIV: no que concerne aos estudos sobre HIV, a InCor, em São Paulo, em sua unidade de imunologia, utiliza algoritmos armazenados em seu banco de dados para realizar análises de padrões de mutação do vírus. Através dessas análises é possível desenvolver vacinas mais eficazes para o tratamento da doença.

3- Nas pesquisas de sistemas que previnem epidemias: no caso da criação de sistemas que combatem epidemias, dados e diagnósticos de pacientes são cruzados na tentativa de detectar com antecedência o surgimento de epidemias em determinadas épocas e lugares.

4- Na prevenção de doenças em tempo real: no que concerne à prevenção em tempo real, as ferramentas que monitoram a glicose, a pressão arterial e os batimentos cardíacos agilizam, através do cruzamentos de dados, os diagnósticos e auxiliam no tratamentos de doenças.

Em relação aos aspectos negativos da utilização dos Big Data, como exemplificamos, na manipulação e venda de dados de usuários de mídias sociais para empresas privadas, temos que: no caso da rede social Facebook, a medida em que os usuários interagem com postagens, através de curtidas e comentários ou utilizam a câmera e o microfone, seus dados são capturados pelo Facebook que os oferece as empresas parceiras. O Facebook ${ }^{11}$ (2018) informa que coleta informações quando os usuários utilizam produtos da plataforma social. Isso envolve desde as informações fornecidas para criar uma conta na rede social até o conteúdo compartilhado e a comunicação com outros usuários. Esses dados são usados pelo Facebook para personalizar anúncios e ofertas de produtos que são oferecidos aos usuários. Através da

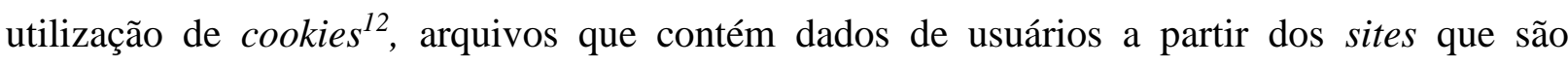


acessados na internet, anúncios publicitários são mostrados aos usuários a fim de recomendar a compra de produtos de empresas parceiras do Facebook. Como mostra o Facebook (2018) ${ }^{13}$ :

[...] os cookies nos permitem mostrar anúncios a pessoas que já visitaram o site de uma empresa, compraram seus produtos ou usaram seus aplicativos, além de nos permitir recomendar produtos e serviços com base nessa atividade. Eles também nos permitem limitar a quantidade de vezes que você vê um anúncio, para não ter que vê-lo repetidamente.

Os anúncios publicitários personalizados são feitos através do cruzamento de dados coletados de usuários do Facebook com dados coletados de sites de empresas parceiras. Essa coleta e direcionamento de dados é realizada utilizando softwares de tecnologias de Big Data.

De acordo com Mayer-Schönberger e Cukier (2013), a utilização dos Big Data e o modo como analisamos a informação transformará a maneira como organizamos e entendemos a sociedade. Um dos pontos principais da utilização dos Big Data é a mudança do foco de análise da causação para a correlação. Os processos envolvidos nos Big Data não focalizam, em geral, as relações de causalidade entre eventos, mas privilegiam as correlações e padrões que não nos dizem o por quê (why) algo ocorre mas, sim, que (what) algo ocorre. Como ressaltam MayerSchönberger e Cukier (2013, p. 7-36), Big Data é sobre o que (what) e não sobre o porquê (why). Nesse contexto, Big Data pode expressar três mudanças principais em diversas áreas do conhecimento, quais sejam:

1- Analisar uma quantidade enorme de dados referentes a um tópico específico ao invés de pequenos conjuntos de informações.

2- 2- Deixa em segundo plano a exatidão e enfatiza a inexatidão de dados que o mundo conectado nos oferece.

3- 3- A relevância está na correlação ao invés de direcionar o foco para a relação causal entre eventos.

A utilização dos Big Data nos propicia analisar mais de perto a realidade através de imprecisão e desordem de dados em comparação com a quantidade pequena de dados e o foco na exatidão. A imprecisão abre espaços para diversos tipos de interações e amplia a perspectiva que temos do mundo. Nesse contexto, as correlações são usadas principalmente pelo setor comercial relacionado às empresas na esfera alimentícia, na saúde e na educação. A correlação pode ser útil para a causalidade porque ela indica o que potencialmente pode estar relacionado ao problema analisado. ${ }^{14}$ 
Conforme ressaltado por MAYER-SCHÖNBERGER; CUKIER (2013), o estudo das correlações amplia as perspectivas da investigação causal, através das variáveis que serão analisadas mediante algoritmos que buscam relações causais, somente que com custos menores, com mecanismos mais baratos e mais rápidos do que os métodos empregados por seres humanos. As tentativas de previsão de eventos futuros são colocadas principalmente na correlação e não na causalidade.

Entretanto, como a correlação nem sempre está relacionada à causação, há maior abertura para a difusão de fake news que, com a expansão da tecnologia da informação e comunicação, são disseminadas de modo rápido e abrangente. Isso porque na análise das variáveis correlacionais, nem sempre há dependência entre as variáveis, nem sempre elas indicam que há uma relação de causalidade entre eventos. Um exemplo de como a correlação pode dar maior abertura para a divulgação de fake news, através do uso de algoritmos, podemos mencionar o fato que ocorreu no carnaval de Notting Hill, em Londres, em 2017. De acordo com Migliacci $(2018)^{15}$, a polícia utilizou um sistema de segurança baseado em algoritimos de reconhecimento facial em busca de supostos terroristas. Entre as 96 pessoas identificadas como terroristas pelo algoritimo, somente uma poderia ser considerada uma ameaça à segurança da sociedade. Em um dos casos, uma mulher foi confundida com um homem. Se supormos que alguém poderia ter postado nas redes sociais as fotos dessas pessoas identificadas como possíveis terroristas, isso poderia causar danos irreparáveis a tais pessoas ou mesmo a morte.

Nesse sentido, nas supostas relações entre eventos que envolvem fake news, como informação falsa compartilhada propositadamente ou sem objetivo de causar danos, não há relação de dependência entre as variáveis que indiquem causalidade. Outros exemplos de como fake news são favorecidas pela correlação, através do uso de tecnologias da informação e comunicação, pode ser notado nas seguintes mensagens divulgadas em redes sociais: "Coco quente mata câncer"16 ou "Suco de quiabo salva cachorro de cinomose e parvovirose"17. Segundo cientistas, não há relação de causalidade entre a cura do câncer e a ingestão de coco quente ou a relação do suco de quiabo com a cura desses dois tipos de doenças que acometem cachorros.

Fake news podem ser caracterizadas como notícias falsas ou não necessariamente falsas, mas que colocam o tema da verdade em segundo plano. Fake news são notícias maquiadas, adulteradas (não totalmente falsas) ou falsas criadas com o intuito de causar danos ou propagadas inintencionalmente. ${ }^{18}$ 
Para Allcott e Gentzkow (2017), fake news podem incluir: notícias que intencionalmente expressam erros; boatos; teorias da conspiração, as quais muitas são difíceis de apurar se são verdadeiras ou falsas; informações que envolvem sátiras; declarações falsas realizadas por políticos e relatórios tendenciosos, mas não completamente falsos.

De acordo com Wardle e Derakhshan (2017, p. 20-22), fake news ${ }^{19}$ correspondem a três tipos de características informacionais:

1- Misinformation - informação falsa, porém ela não é criada e nem compartilhada com a intenção de causar danos.

2 - Desinformation - informação falsa e criada propositadamente com o objetivo de prejudicar um indivíduo, grupo sociais, organizações ou países.

3- Mal-information - informação baseada em fatos, porém usada estrategicamente para prejudicar pessoas, organizações ou países. ${ }^{20}$

Podemos mencionar alguns casos de fake news ocorridos no Brasil, envolvendo misinformation, disinformation e mal-information e que ganharam ampla repercussão. No caso de fake news com conteúdo que contém misinformation podemos citar novamente as mensagens que circulam nas redes sociais atribuindo à mistura de água, flocos, suco e extrato de coco quente poder para matar as células de câncer. (DOMINGOS, 2018). ${ }^{21}$ Fake news sobre uma receita caseira de suco de quiabo cura cachorros acometidos das doenças de cinomose ou de parvovirose. $^{22} \mathrm{Ou}$ ainda, fake news que circulam nas redes sociais afirmando que a barra colorida nas caixas de leite seriam indícios de produtos vencidos que teriam retornado ao mercado. (VELASCO, 2018). ${ }^{23}$

Já no que concerne às fake news com conteúdo relacionado à disinformation, podemos mencionar a disseminação de notícias falsas sobre a vereadora Marielle Franco, assassinada no Rio de Janeiro, em março de 2018. Uma das diversas fake news disseminadas sobre Marielle afirma que ela é ex-mulher do traficante de drogas Marcinho VP. (SANTOS, 2018). ${ }^{24}$ A transformação de uma informação irônica em fake news, que se propagou pelas redes sociais em forma de boato e teoria da conspiração, usada com objetivos políticos, relacionada ao chamado "Plano URSAL" (União das Repúblicas Socialistas da América Latina) e que ganhou amplitude após ser proferida em um debate entre presidenciáveis, realizado pela emissora de TV - Band, em 2018. (NOGUEIRA, 2018). ${ }^{25} \mathrm{Ou}$ ainda, a propagação de fake news sobre uma mulher chamada Fabiane Maria de Jesus, acusada de sequestrar crianças para praticar feitiçaria. Essa acusação infundada, baseada em fake news, deu suporte e vazão para a ação regada de ódio por 
dezenas de pessoas, o que acarretou na sua morte por linchamento na cidade do Guarujá, em São Paulo, em 2014. A divulgação da fake news por uma página no Facebook intitulada Guarujá Alerta - proporcionou o seu linchamento virtual e, posteriormente, o seu espancamento e morte. (MOREIRA, 2014). ${ }^{26}$

No que se refere às fake news com conteúdo relacionado à mal-information, mencionamos um vídeo que circula nas redes sociais sobre uma multidão de venezuelanos na fronteira com a Colômbia. As imagens são verdadeiras, a multidão estaria em San Antonio del Táchira, cidade fronteiriça entre Venezuela e Colômbia. Entretanto, a legenda que acompanha o vídeo que circula nas redes sociais afirma que "uma multidão de venezuelanos estariam invadindo a fronteira com o Brasil”. (JULIÃO, 2018). ${ }^{27}$

Como sabemos fake news não surgiram com o advento da internet, elas são tão antigas quanto à civilização; porém, fake news ganharam amplitude através do desenvolvimento das tecnologias digitais da comunicação. Inicialmente a tecnologia incipiente possibilitou que fake news fossem disseminadas através das mídias tradicionais como jornais impressos, rádios e emissoras de TVs que, muitas vezes, utilizaram-se e ainda se utilizam de fake news para manipulação da opinião pública e direcionamento da ação coletiva. Posteriormente, com o advento da internet, o campo de abrangência de fake news aumentou drasticamente, além de proporcionar a popularização do termo, que ocorreu durante a eleição presidencial norteamericana, em 2016.

Atualmente a manipulação e disseminação de fake news está se encaminhando para atingir outro patamar - deep fake news (falsificação profunda) - que são informações falsas, manipuladas com o auxílio da inteligência artificial. (ALMEIDA; DONEDA; LEMOS, 2018). Um exemplo de deep fake news é o vídeo da ex-primeira dama dos EUA, Michelle Obama, despindo-se em frente à uma câmera. O vídeo surgiu em fórum online - Reddit - e foi produzido por um programa de inteligência artificial denominado FakeApp. No vídeo o rosto de Michelle Obama foi sobreposto ao corpo de uma atriz de filmes pornográficos. (ROOSE, 2018, tradução de Claudia Bozzo). ${ }^{28}$

Se considerarmos que vídeos podem ter impacto emocional mais profundo e abrangente do que imagens ou linguagens escritas, as consequências negativas da manipulação de deep fake news são mais devastadores do que fake news, tanto para reputação individual quanto para a sociedade assentada em pilares democráticos. Como salientam Almeida, Doneda e Lemos $(2018)^{29}$, vídeos falsos de policiais atirando em civis ou de supostos bandidos assaltando 
pessoas em uma comunidade poderia causar uma convulsão social. O tempo de denúncia e da apuração dos vídeos para verificação de autenticidade seria um empecilho para conter o caos social, pois nesse ínterim entre a disseminação dos vídeos e sua verificação, mortes poderiam ocorrer, como linchamentos de inocentes ou embates entre policiais e civis provocados pela divulgação de deep fake news em maiores proporções em comparação ao que já acontece, em contextos diferenciados.

Interessa-nos, neste texto, investigar a influência que fake news, através de mídias sociais, exercem na percepção-ação coletiva. Tendo como suporte teórico o paradigma da complexidade, no tópico seguinte, analisamos os impactos de fake news nas propriedades da percepção-ação, quais sejam: prospectividade, flexibilidade e coordenação emergente.

\section{FAKE NEWS E PERCEPÇÃO-AÇÃO COLETIVA: UMA ANÁLISE A PARTIR DO PARADIGMA DA COMPLEXIDADE}

"No mundo realmente invertido, o verdadeiro é um momento do falso." (DEBORD, p.16, 2003).

O paradigma da complexidade é constituído por diversas características, entre as quais estão: o princípio hologramático, a emergência enquanto formação não linear de padrões, a transdisciplinaridade na investigação dos fenômenos, etc. (MORIN, 1995; 2005). A emergência, enquanto formação não linear de padrões, é a característica que se sobressai, particularmente neste texto, na investigação da relação entre fake news e percepção-ação coletiva.

A emergência pode ser caracterizada como um processo de formação de padrões, originados através da interação sinergética (diferenciação + integração= sinergia) e autoorganizada entre elementos distintos que constituem um sistema. A partir da relação sinergética e auto-organizada, padrões distintos formarão níveis integrativos de organização, os quais são direcionados pela evolução dinâmica do sistema. Nesse sentido, a emergência envolve a criação de algo novo que não pode ser reduzido às propriedades individuais das partes. As propriedades emergentes só podem ser observadas como uma estrutura global. Através do processo de emergência que ocorre no plano micro, a partir da interação e cooperação entre os elementos, surge o plano macro de organização.

No contexto da relação entre ambos plano micro e macro está a fase de transição entre ordem e desordem, caracterizada pela relação entre os elementos de um sistema complexo. ${ }^{30}$ Podemos ilustrar essa dinâmica, por exemplo, em sociedades nas quais há a transição de um 
sistema escravocrata para outro no qual existem direitos civis, no espaço de transição entre Estados considerados democráticos e Estados com regimes autoritários, na transição entre períodos de paz e guerras entre as nações, etc.

Através do processo de emergência surgem parâmetros de ordem e de controle. Segundo Gonzalez ${ }^{31}$, os parâmetros de ordem e de controle emergem a partir de padrões informacionais intrínsecos e oriundos da interação e inter-relação entre elementos distintos que compõem um sistema dinâmico e auto-organizado. Para ela, a relação dinâmica entre organismos e meio ambiente pode ser abordada filosoficamente do seguinte modo: os organismos pertencem a um sistema dinâmico, ou seja, fazem parte de um universo complexo, constituído de inúmeras naturezas "distintas" que se auto-organizam. A partir do fluxo informacional intrínseco e oriundo da inter-relação dinâmica entre essas naturezas distintas surgem parâmetros de controle, caracterizados pela implementação de hábitos que, por sua vez, darão origem aos parâmetros de ordem constitutivos de organizações coletivas.

Entendemos que a quebra de hábitos de ação pode criar novos fluxos informacionais e, consequentemente, novos parâmetros de ordem responsáveis pelo redirecionamento do comportamento de agentes inseridos no ambiente. De acordo com Haken (1988, p. 45), parâmetros de ordem podem ser caracterizados como: "propriedades emergentes da interação dinâmica entre elementos no micro-nível. Quando os parâmetros de ordem emergem, eles escravizam o comportamento de elementos individuais, produzindo novas características na escala macroscópica." 32

Nesse sentido, retomamos o problema direcionador da nossa investigação: qual a influência da disseminação de fake news, disponíveis nos meios digitais, na percepção-ação coletiva? Consideramos que a implementação de hábitos coletivos, através da emergência de padrões de ordem e controle, oriundos da disseminação e manipulação de fake news, podem ter impactos negativos nas propriedades de flexibilidade, prospectividade e coordenação emergente da percepção-ação humana.

Podemos pensar na implementação de hábitos e na emergência de possíveis padrões coletivos de ação através da disseminação de fake news, por exemplo, nos contextos de disputas eleitorais. Para exemplificar, mencionamos as influências que fake news tiveram na eleição norte-americana de 2016.

No caso da eleição norte-americana, como ressaltamos, a empresa britânica Cambridge Analytica usou dados de usuários do Facebook baseados em gênero, raça e idade para traçar o 
perfil dos eleitores americanos, potenciais alvos de métodos desenvolvidos pela empresa (baseados na correlação e combinação de dados pessoais) para influenciar e angariar votos para o candidato Donald Trump, através da disseminação de fake news. A campanha eleitoral de Trump utilizou os serviços da Cambridge Analytica para coletar mais de 50 milhões de dados de usuários do Facebook com a finalidade de influenciá-los com propaganda política direcionada.

No caso do Cambridge Analytica, os dados foram coletados principalmente através de um aplicativo que realizava teste de personalidade. Estudos também indicam que entre $85 \%$ a 95\% das análises realizadas através dos likes no Facebook obtêm resultados precisos em distinguir entre usuários negros ou brancos, homens ou mulheres, homossexuais ou heterossexuais, Republicanos ou Democratas, etc. (HINDMAN, 2018). ${ }^{33}$ Segundo Martí (2018), os dados dos usuários do Facebook foram repassados para a Cambridge Analytica, sem a autorização da empresa de Mark Zuckerberg. Ao tomar conhecimento de que o aplicativo coletava dados de usuários para fins espúrios, fora de pesquisas de âmbito acadêmico, o Facebook excluiu o aplicativo e exigiu que a Cambridge Analytica apagasse os dados coletados indevidamente. Esses dados não foram deletados, foram repassados, influenciando a campanha de Donald Trump. ${ }^{34}$

De acordo com Zhao et. al. (2018), nas pesquisas realizadas pelo Pew Center, 44\% dos americanos obtém notícias através do Facebook. Além disso, na eleição norte-americana de 2016, o BuzzFeed News Analysis informou que, através de uma pesquisa envolvendo três páginas de cunho político de direita e três páginas politicamente orientadas à esquerda, 38\% das informações compartilhadas pelas páginas direitistas incluíam fake News comparada à $19 \%$ do conteúdo que incluía fake news das páginas esquerdistas. Segundo a análise realizada pelo BuzzFeed, as páginas de direita contribuíram para a ascensão política de Donald Trump porque elas receberam a atenção de internautas, propiciando a essas páginas um poder de alcance semelhante aos noticiários de TVs a cabo, nos EUA. (SILVERMAN, et al., 2016). ${ }^{35}$ Segundo Zhao et. at. (2018), outra característica de fake news é que elas são disseminadas a partir de diversas fontes, diferentemente das notícias baseadas em fatos, as quais são propagadas a partir de fontes singulares. ${ }^{36}$

Para Allcott e Gentzkow (2017), estudos recentes mostram que 62\% dos norteamericanos adultos usam mídias sociais. Dentre essas plataformas, o Facebook se destaca como aquela onde mais se compartilharam fake news nas eleições norte-americanas. Ao tomarem 
contato com fake news, muitas pessoas acreditam que as notícias são ancoradas em fatos e que, portanto, são reais. Ainda, a maior parte de fake news compartilhadas e debatidas nas mídias sociais favoreceu o candidato Donald Trump.

Um exemplo de fake news, caracterizada como disinformation ${ }^{37}$, disseminadas na eleição presidencial norte americana, a qual pode ter influenciado eleitores a votarem em Donald Trump, foi publicada por um website denominado WTOE 5 News. A notícia, que teve milhares de compartilhamentos, afirmava que o papa Francisco apoiava a candidatura de Trump à presidência. O site de checagem de fake news - Snopes - apurou a fonte de onde a notícia foi originada e confirmou a sua inveracidade. (EVON, 2016). ${ }^{38}$ Outro exemplo de fake news, caracterizada como disinformation, que circulou nas redes sociais durante a eleição norteamericana estava relacionada à candidata Hillary Clinton, a qual, segundo fake news, havia sido diagnosticada com sintomas da doença de Parkinson. O site de checagem de fake news Snopes $^{39}$ confirmou que a notícia era baseada em crenças infundadas. (EMERY, 2016). ${ }^{40}$

Ainda que não se tenha um consenso sobre a influência de fake news no comportamento do eleitorado norte-americano e no resultado das eleições realizadas em 2016, da qual Trump foi vitorioso, entendemos, no âmbito do escopo deste texto, que a disseminação de fake news pode ter sido um dos fatores que contribuíram para a vitória de Trump nas eleições. Consideramos que através disseminação de fake news relacionadas à corrida presidencial norteamericana, podemos tecer uma breve análise contextualizada em 3 pontos centrais que se interconectam:

(1) Fake news proporcionam contágio emocional que se propaga através de redes sociais.

(2) A emergência de padrões coletivos de ação, fundamentados no contágio emocional, têm impactos nas propriedades de prospectividade, flexibilidade e coordenação emergente da percepção-ação.

(3) A emergência de padrões coletivos de ação oriundos da não presencialidade nas redes sociais virtuais podem dificultar a percepção de affordances.

Em relação a (1), o experimento de contágio emocional realizado pelo Facebook, em 2014, mostrou que as redes sociais podem manipular informações e, consequentemente, as emoções dos usuários. De acordo com Kramer, Guillory e Hancock (2014), nesse experimento foi demonstrado que os padrões emocionais dos usuários do Facebook alteravam de acordo com os padrões emocionais de outros usuários, expostos através de postagens. Isso sem a necessidade da presença corporal e da comunicação não verbal. Este teste evidenciou a 
possibilidade de contágio emocional em ampla escala, via redes sociais.

Esta ausência de interação corporal e não verbal traz consequências para os usuários de redes sociais, permitindo, mais precisamente, certo controle e manipulação de suas emoções e ações. O contágio emocional, no caso das eleições norte americanas, foi direcionado por crenças infundadas - fake news - as quais confundem e desconfirmam evidências empíricas, propiciando a emergência de padrões e hábitos coletivos, direcionadores de ações que, possivelmente, influenciaram no resultado das eleições.

Esses padrões coletivos de ação - como indicado em (2) - impactam nas propriedades de prospectividade, retrospectividade e coordenação emergente da percepção-ação.

Se considerarmos o exemplo das eleições norte americanas, podemos supor que a disseminação de fake news de que o papa apoiava Trump ou de que Clinton tinha sintomas da doença de Parkinson pode ter contribuído para alterar padrões coletivos da percepção-ação dos eleitores. Essa modificação ocorre através da emergência de padrões de controle no micro-nível. A alteração no plano micro de ação dos eleitores, possivelmente podem alterar os padrões de ordem do plano macro, possibilitando a emergência de novos padrões. A emergência desses padrões de controle criam hábitos sociais, possibilitando mudanças nas propriedades de prospectividade, flexibilidade e na coordenação emergente da percepção-ação coletiva.

$\mathrm{O}$ conceito de ação coletiva está relacionado à capacidade dos organismos de agirem conjuntamente, preservando certo grau de autonomia individual. Tendo como base os trabalhos de Eleonor Gibson (1993) e Pacharie (2007; 2014), entendemos que hábitos coletivos que emergem da disseminação de fake news podem diminuir a autonomia, alterando as propriedades de prospectividade, flexibilidade e de coordenação emergente da ação coletiva. Eleonor Gibson (1993) caracteriza a prospectividade como propriedade antecipatória da ação. A antecipação direciona a ação e a atenção para as características emergentes de diversas situações. Já a flexibilidade é caracterizada como a capacidade que organismos têm de encerrar uma ação, quando as circunstâncias surgem desfavoráveis. No que concerne à coordenação emergente, ela ocorre entre indivíduos, os quais não têm planos para agirem conjuntamente. A coordenação emergente está relacionada à percepção-ação, à ação simulada e à ação sincronizada involuntariamente. Na coordenação emergente, o comportamento coordenado ocorre devido à percepção que realiza ações individuais múltiplas de modo similar. A ação sincronizada pode ser realizada entre dois indivíduos involuntariamente e mesmo na ausência de um acoplamento mecânico. (PACHARIE, 2014). 
Nossa hipótese é a de que: no que concerne à propriedade de flexibilidade da ação coletiva, por não haver interação corporal direta nas redes sociais como Facebook, novos hábitos coletivos são criados, dificultando - como indicado em (3) - a percepção de affordances oriundas de trocas informacionais presenciais.

O conceito de affordance é caracterizado por Gibson (1986) como possibilidades de ação que o ambiente oferece ao agente situado e incorporado. Nas palavras de Gibson (1986, p.12, tradução nossa), affordance "envolve a complementaridade do animal e do meio ambiente." 41 Através da complementaridade organismo-ambiente, perceber affordances é perceber diretamente a informação significativa para a ação. Em outras palavras, perceber affordances é detectar a informação disponível no ambiente de um modo específico, direto, não inferencial. (LARGE, 2003).

Affordances caracterizam o modo como o organismo vive, constituindo o seu nicho, o qual, por sua vez, expressa o processo co-evolutivo organismo-ambiente. Semelhantemente ao paradigma da complexidade, estudos sobre affordances buscam expressar uma visão de mundo não fragmentada, na qual os organismos não são considerados partes isoladas do ambiente que habitam, mas são seres que compartilham padrões informacionais coletivos que especificam e direcionam os seus comportamentos em nichos sistêmicos.

Nesse sentido, consideramos que a flexibilidade seria prejudicada porque no ambiente virtual não há possibilidade de controle e de escolha da ação através da percepção direta de diferentes tipos de affordances sedimentadas na relação presencial corpo-ambiente.

Em relação à prospectividade, que é a propriedade antecipatória da ação, ela poderia ser prejudicada e diminuída no ambiente virtual. Isso porque a manipulação de fake news pode comprometer a antecipação da ação no que concerne à percepção da informação, ao direcionamento da ação e à atenção para características emergentes das diversas situações experienciadas pelos usuários de redes sociais. No que concerne à coordenação emergente, é nossa hipótese que a manipulação da informação oriunda dos Big Data, veiculadora de fake news, ocasionaria maior controle das ações individuais e coletivas, múltiplas e coordenadas. Isso porque a manipulação da informação poderia prejudicar a ação sincronizada espontaneamente e involuntariamente entre indivíduos. Isso propicia aos manipuladores de fake news minimizarem a individualidade de cada agente, abrindo espaço para que as singularidades sejam diluídas em uma coletividade "cega" e controlada virtualmente.

Entendemos que fake news, ao serem manipuladas e disseminadas em nichos virtuais, 
podem alterar a percepção-ação dos seres humanos e consequentemente as relações coletivas nos seus nichos ecológicos. Isso porque fake news, enquanto informações que conectam agentes aos seus nichos, propiciam o estabelecimento de padrões de ação coletiva, os quais afetam o sistema, criando pontos de instabilidade.

\section{CONSIDERAÇÕES FINAIS}

Neste trabalho nos propomos a investigar a relação entre fake news, padrões informacionais e percepção-ação coletiva, a partir do paradigma da complexidade. Procuramos entender como a disseminação de fake news pode contribuir para o surgimento de padrões que direcionam a ação humana no plano coletivo.

Nossa hipótese principal é a de que fake news, disseminadas em nichos digitais, propiciam o surgimento de padrões informacionais no âmbito coletivo, podendo alterar hábitos sociais ancorados em nichos ecológicos. Essa mudança de padrões de ação coletivos e hábitos sociais está relacionada à possível influência que a manipulação de fake news exerce nas propriedades de prospectividade, flexibilidade e coordenação emergente da percepção-ação.

Procuramos fundamentar nossa hipótese usando como exemplo o papel que fake news, disseminadas principalmente via redes sociais como o Facebook, desempenharam nas eleições norte-americanas de 2016. Consideramos que a manipulação e propagação de fake news não foi o motivo principal da eleição de Trump nos EUA, mas influenciou consideravelmente na opinião pública, através do contágio emocional e da emergência de padrões informacionais, direcionadores da ação coletiva.

Como apontamos, a emergência de padrões informacionais no âmbito coletivo, propicia a alteração de hábitos sociais ancorados em nichos ecológicos. Podemos mencionar como exemplos de hábitos sociais a prática da solidariedade, a cooperação, o diálogo presencial estabelecido entre pessoas conhecidas e desconhecidas nas atividades do cotidiano ou em contextos relacionados às atividades pontuais, como debates entre candidatos em épocas de eleições, etc. Consideramos que a alteração de hábitos sociais causada pela disseminação de fake news em nichos virtuais pode ser expressa através de aspectos negativos, tais como:

1- Inibição da prática de solidariedade e de cooperação entre indivíduos - fake news estimulam, na maioria das vezes, a indiferença e a agressividade em relação ao outro. Exemplos dessa indiferença e agressividade podem ser observados: na naturalização da violência, principalmente contra a mulher, como no caso em que citamos, no qual uma mulher chamada 
Fabiane Maria de Jesus foi acusada de feitiçaria, linchada e morta. Na indiferença referente à escolha de candidatos em épocas de eleições, a qual se expressa em votos nulos, brancos e abstenções, como ocorreu nas eleições presidenciais brasileiras realizadas em 2018, cuja porcentagem de votos nulos, brancos e abstenções, segundo Grandin, Esteves e Oliveira $(2018)^{42}$, alcançou 42,1 milhões dos votos válidos. Ou ainda, na campanha eleitoral para presidência dos EUA, a qual teve como imagem preponderante a agressividade nos discursos, principalmente proferidos por Donald Trump, os quais evidenciavam misoginia e racismo. Em uma de suas afirmações, Trump chegou a dizer que mulheres que fazem aborto deveriam sofrer algum tipo de punição. (MONGE, 2016). ${ }^{43}$

2- Desvalorização do diálogo presencial - ao inibir a prática da solidariedade e da cooperação entre indivíduos, hábitos de dialogar cotidianamente ao ir comprar um jornal na "banca da esquina" ou em contextos pontuais, como debates eleitorais, são substituídos pelo consumo de notícias online (nem sempre ancoradas em fatos) ou, como ocorreu nas eleições presidenciais brasileiras em 2018, pela fuga de debates, dando preferência para comunicação online, muitas vezes baseadas em fake news. Nas eleições presidenciais ocorridas no Brasil em 2018, o então candidato Jair Bolsonaro (PSL) se negou a participar de debates com o candidato Fernando Haddad (PT) no segundo turno das eleições, alegando restrições à sua condição de saúde. ${ }^{44}$

3- Alteração do hábito de votar provocada pela polarização política propiciada por grupos hiperpartidários - fake news disseminadas por grupos hiperpartidários, por exemplo, favorecem a polarização política, podendo alterar o hábito social comumente associado ao ato de votar. Eleitores influenciados por fake news são estimulados a não votarem ou propícios a votarem com raiva, medo, desespero etc. ${ }^{45}$ Exemplo de polarização política que estimula a agressividade pode ser observada no caso da morte do capoeirista Romualdo Rosário da Costa, conhecido como Moa do Katendê, assassinado a golpes de faca, no período das eleições de 2018, por um simpatizante de Jair Bolsonaro (PSL), após Moa do Katendê declarar voto no candidato Fernando Haddad (PT). ${ }^{46}$

Nesse sentido, a disseminação de fake news altera hábitos coletivos na medida em que, através da manipulação da opinião que favorece o "comportamento de manada" 47 , propicia o surgimento de padrões informacionais que inibem a prática da solidariedade, da cooperação e desvaloriza o diálogo presencial, prejudicando as propriedades de coordenação emergente, prospectividade e flexibilidade. Isso porque a solidariedade, a cooperação e o diálogo entre indivíduos estão ancorados em relações sincronizadas que emergem espontaneamente e 
involuntariamente, bem como a capacidade de encerrar uma ação considerada desfavorável e a antecipação de determinada ação a fim de que haja um direcionamento adequado do comportamento coletivo.

A novidade não é a manipulação de fake news, que não são produtos da sociedade contemporânea, mas o modo como são disseminadas. Com o desenvolvimento das tecnologias digitais da informação e da comunicação, as mídias virtuais se tornaram quase que “onipresentes”. Nossas ações passaram a ser mediadas e, de certa forma, controladas através de tecnologias digitais. Sem a presencialidade nas relações humanas, os fatos tem mais possibilidade de serem considerados secundários em comparação às crenças pessoais. Isso porque consideramos que a percepção não é predominantemente cerebral, mas envolve principalmente o corpo situado no ambiente. Na obra The embodied mind, Varela et al. (1991), desenvolvem o conceito de enaction, o qual expressa que a percepção é baseada em ação guiada através de estruturas cognitivas que emergem dos padrões sensório-motores na relação corpoambiente. Essas estruturas cognitivas não são representadas, mas incorporadas na ação que surge do acoplamento da nossa estrutura corporal com o ambiente. (MORONI, 2014, p. 232). Como ressaltam Varela et al. (1991, p. 172-173, tradução nossa):

Permita-nos explicar o que nós queremos dizer pela expressão ação incorporada. Ao empregar o termo incorporado, nós queremos salientar dois pontos: primeiro, que a cognição depende dos tipos de experiência que vêm de um corpo com várias capacidades sensório-motoras e, segundo, que essas capacidades sensório-motoras consideradas individualmente estão inseridas em um amplo contexto biológico, psicológico e cultural. ${ }^{48}$

Apesar das diferenças ${ }^{49}$ entre a concepção proposta por Varela et al. (1991) e àquela concebida por Gibson (1986) em relação à percepção, as quais não são temas de estudo deste trabalho, ambas presumem que a percepção é panorâmica na medida em que não envolve somente o cérebro, mas o corpo situado no ambiente. Nesse sentido, tanto para Gibson (1986) quanto para Varela et al. (1991), a percepção envolve o sistema organismo-ambiente e seu background evolutivo.

$\mathrm{Na}$ teoria gibsoniana, a apreensão do significado advém da percepção de affordances possibilitada através do acoplamento entre as estruturas corpóreas do organismo e as estruturas invariantes do ambiente. Nesse sentido, há uma relação de acoplamento e mutualidade que se estabelece entre organismo e ambiente. Como apontam Michaels e Carello, 1981, p.42, tradução 
nossa): “[...] poderia-se dizer que uma affordance é o que o ambiente significa para um perceptor"[...] Detectar affordances é, simplesmente, detectar significado."50

Nesse contexto, sem a presencialidade nas relações humanas, as crenças pessoais tomam o lugar de prioridade em relação aos fatos. Isso porque a percepção direta de affordances e, consequentemente, do significado ficam prejudicadas na medida em que não há a presença do corpo nas relações. Sem a presença do corpo nas relações, as crenças pessoais tem mais probabilidade de se tornarem autoverdades quase que inquestionáveis, fundamentadas em estados emocionais, os quais são influenciados por fake news, disseminadas por grupos pautados por interesses específicos. Através de mídias sociais virtuais, fake news são espalhadas com o intuito de direcionar a ação, via contágio emocional.

Assim, entendemos que fake news, enquanto crenças infundadas, ancoradas parcialmente na realidade ou sem vínculos com fatos, propiciam alterações em estados emocionais humanos, no plano coletivo, através do contágio emocional. A proliferação do contágio emocional cria padrões informacionais coletivos, os quais impactam nas propriedades de prospectividade, flexibilidade e coordenação emergente da percepção-ação. A emergência de padrões de ação coletivos possibilita o estabelecimento de hábitos sociais, oriundos da nãopresencialidade nas redes sociais virtuais, dificultando a percepção de affordances no ambiente ecológico.

A dificuldade na percepção direta de affordances está relacionada à diminuição do grau de ação autônoma, a qual é prejudicada pelo estabelecimento de padrões coletivos direcionados por fake news. Na perspectiva ecológica, o conceito de ação autônoma está associado ao conceito de affordance. Edward Reed (1996, p. 11) afirma que a proposta ecológica visa entender como os organismos constroem seus caminhos no mundo de forma autônoma, não mecânica. O mundo é repleto de affordances e, ao perceber a informação expressa por essas affordances, os organismos agem no ambiente delimitando as suas ações em função de cada contexto específico. O conceito de ação autônoma na perspectiva ecológica envolve intenção, que não é caracterizada em termos de estados mentais, representações e causa-efeito, mas em termos de affordances e informação. Como ressalta Reed (1993, p. 62, tradução nossa):

Da perspectiva ecológica, intenções não são causas da ação, mas padrões de organização da ação; elas não são mentais em oposição ao físico; ao contrário, são incorporadas nos tipos de desempenhos mais comumente encontrados em criaturas com capacidades cognitivas. ${ }^{51}$ 
Essa passagem de Reed mostra que os padrões intencionais de organização emergem quando o agente tem possibilidade de escolha da ação, através da percepção de diferentes tipos de affordances. Desse modo, padrões intencionais, via percepção direta, são responsáveis por selecionar affordances, direcionando e controlando ações de agentes situados e incorporados para objetivos específicos. (WITHAGEN et al, 2012, p. 253).

Em perspectiva do que aconteceu nas eleições norte-americanas em 2016 e do que ocorreu nas eleições presidenciais brasileiras em 2018 (a qual será tema de estudo de um trabalho posterior), no que concerne à disseminação de fake news, entendemos que: a emergência de padrões intencionais, no contexto social (não digital), é alterada porque padrões informacionais coletivos oriundos de crenças infundadas, no plano digital, interferem e diminuem a ação autônoma. Ao interferirem na ação autônoma, os padrões informacionais coletivos, oriundos de fake news disseminadas em sites, blogs e redes sociais virtuais como o Facebook, prejudicam a percepção de affordances na medida em que alteram padrões intencionais e o autocontrole humano. Consideramos que dois dos possíveis motivos dessa alteração estão ligados à diminuição da capacidade de antecipação e de sincronização espontânea da ação coletiva.

Diante da perspectiva da influência negativa da disseminação e manipulação de fake news na ação autônoma, se considerarmos que a autonomia, segundo Gonzalez et al. (2014, p. 163, tradução nossa), “não é caracterizada em termos de ausência de restrições, mas como acordos consensuais estabelecidos entre agentes para o benefício de todos" ${ }^{2}$, os possíveis impactos futuros para a democracia não são vistos como promissores. Ao alterarem os padrões intencionais e diminuírem o autocontrole de indivíduos, fake news interferem negativamente na percepção do ambiente social (não virtual), prejudicando a autonomia e favorecendo o controle coletivo por Estados com sistemas de governos assumidamente autoritários ou com tendências autoritárias. Esse controle modifica hábitos sociais na medida em que interfere na sincronização espontânea da ação coletiva, gerando, através do "comportamento de manada", redes de colaboração voltadas a interesses políticos espúrios.

Um dos exemplos dessa interferência prejudicial na sincronização espontânea, através do "comportamento de manada", é a centralização da divulgação de informações governamentais em redes sociais como o Twitter. Presidentes de países como EUA ${ }^{53}$ e Brasil ${ }^{54}$ utilizam o Twitter para transmitir suas decisões políticas ao povo, incentivando a descredibilidade em relação a outros meios de comunicação tradicionais como jornais, revistas 
e noticiários de TV, considerados adversários desses governos e divulgadores de fake news. Ao desacreditarem outras fontes de informação, posicionando-se como líderes que não podem ser criticados sem providenciarem algum tipo de desforra, esses líderes rechaçam a democracia, promovendo a aceitação acrítica de suas decisões pelos seus seguidores.

Não consideramos que as informações divulgadas pelos meios de comunicação tradicionais são piamente confiáveis e que, portanto, não devem ser criticadas; pelo contrário, deve haver sempre espaço para a existência de um ambiente que incentive o diálogo crítico, construtivo e atento às mudanças. A ausência de críticas às mídias tradicionais que também divulgam fake news ${ }^{55}$, identicamente à governos com tendências autoritárias, alimenta o “comportamento de manada". Não se trata de ingenuidade quanto ao poder midiático, capaz de derrubar governos democráticos. Assim como criticamos a agressividade promovida pela mídia, também discordamos do modo, muitas vezes hostil, através do qual governos considerados democráticos tem tratado as críticas recebidas pela mídia, influenciando apoiadores a desconsiderarem outras fontes de informação que não sejam alinhadas aos rumos desses governos.

No decorrer desses acontecimentos, faz-se necessário que sejam elaboradas e aplicadas, com urgência, maneiras de conter a diminuição de nossa autonomia e de nosso autocontrole, bem como reter a crescente transformação e manipulação perniciosa de nossos hábitos sociais através da disseminação de informações espúrias em nichos virtuais.

\section{NOTAS}

Gostaria de agradecer o parecerista ou a parecerista, cujo olhar atento e sugestões contribuiram para o aprimoramento deste trabalho.

${ }^{2}$ Optamos, neste texto, por utilizar o termo de língua inglesa - fake news - sem traduzir para a língua portuguesa. Comumente o termo fake news é traduzido como notícias falsas. Entretanto, consideramos que o significado da expressão fake news é mais abrangente do que a tradução que é geralmente usada na língua portuguesa. Isso porque o adjetivo falso, de acordo com o dicionário Aurélio, é caracterizado como: “contrário à verdade; sem correspondência com a realidade. Que oculta o que realmente pensa. Que aparenta ser real, mas não é; cujo conteúdo foi adulterado, modificado; feito por imitação; desprovido de fundamento, de exatidão; [..]".(Fonte:< https://www.dicio.com.br/falso/ >). Nesse sentido, o termo fake news se torna significativamente mais amplo dado que engloba tanto notícias falsas, como também notícias não totalmente falsas, mas que tem alguma correspondência com a realidade, criadas e disseminadas com objetivo de causar prejuízos ou propagadas inintencionalmente.

${ }^{3}$ Data are a form of power. (ILIADIS; RUSSO, p. 1, 2016).

${ }^{4}$ Fonte: < https://www.nexojornal.com.br/expresso/2018/05/25/O-que-diz-a-nova-lei-de-prote\%C3\%A7\%C3\%A3ode-dados-da-Europa.-E-o-efeito-no-Brasil $>$.

${ }^{5}$ Convém ressaltar que se se a "Lei de proteção de dados" não entrar em vigor no Brasil, tanto para empresas públicas quanto para empresas privadas, pode gerar problemas de ordem política e econômica, uma vez que leis de proteção de dados já são realidade em outros países, como nos Estados membros na União Europeia (UE). Se o 
Brasil não padronizar as leis de proteção de dados com as leis de nenhum país de relevância econômica no mundo terá problemas em realizar transações comerciais. A troca de dados entre Brasil e países com legislações que asseguram a proteção de dados ficaria impossibilitada sem uma lei adequada que garanta a segurança dos dados por aqui. (RONCOLATO, 2018). Caso a "Lei de proteção de dados" não entre em vigor no Brasil, empresas brasileiras podem ser alvo de processos judiciais por parte de empresas e indivíduos estrangeiros que tiverem seus dados coletados e utilizados por brasileiros.

${ }^{6}$ Fonte: $<$ https://www.brasildefato.com.br/2018/07/14/empresa-que-vazar-dados-de-clientes-pode-ser-multada-emate-rdollar-50-milhoes/ $>$.

${ }^{7}$ Fonte: $\lfloor$ http://agenciabrasil.ebc.com.br/geral/noticia/2018-08/lei-de-protecao-de-dados-trara-impactos-pessoasempresas-e-governos $>$.

${ }^{8}$ Fonte:〈https://www.intel.com.br/content/dam/www/public/lar/br/pt/documents/articles/e7-big-data-planningguide-webready-por.pdf $>$.

${ }^{9}$ Optamos por manter as palavras na terminologia inglesa. Não é nosso propósito, neste trabalho, realizar um estudo pormenorizado acerca das tecnologias de Big Data, mas apenas mencioná-las como suporte teórico a proposta central do texto.

${ }^{10}$ Fonte: $\langle$ https://www.forbes.com/sites/gilpress/2016/03/14/top-10-hot-big-data-technologies/\#4eb00dc765d7 $>$.

${ }^{11}$ Fonte: $\langle$ https://www.facebook.com/about/privacy/update $>$.

${ }^{12}$ Fonte: $<$ https://seguranca.uol.com.br/antivirus/dicas/curiosidades/o-que-sao-cookies-e-como-eles-podem-meprejudicar.html\#rmcl $>$.

${ }^{13}$ Fonte: $\langle$ https://www.facebook.com/policies/cookies/ >.

${ }^{14}$ Não é o propósito deste trabalho realizar um estudo pormenorizado acerca da correlação e da causalidade.

${ }^{15}$ Fonte: $<\quad$ https://www1.folha.uol.com.br/tec/2018/09/nao-acredite-cegamente-em-algoritmos-porque-ate-eleserram.shtml $>$.

${ }^{16}$ Fonte: $<$ https://g1.globo.com/fato-ou-fake/noticia/2018/12/05/e-fake-mensagem-que-diz-que-coco-quente-matacancer.ghtml $>$.

${ }^{17}$ Fonte: <https://g1.globo.com/fato-ou-fake/noticia/2018/12/11/e-fake-que-suco-de-quiabo-salva-cachorro-decinomose-e-parvovirose.ghtml $>$.

${ }^{18}$ Fonte: Informação verbal dada pela $\operatorname{Prof}^{a} \operatorname{Dr}^{a}$ Maria Eunice Quilici Gonzalez em junho de 2018.

${ }^{19}$ Fake news estão inseridas dentro de um panorama mais abrangente caracterizado como desordem informacional. Diante das várias facetas de fake news, o relatório produzido por encomenda do Conselho da Europa em Estrasburgo, em 2017, recomendou que se adote o termo desordem informacional para expressar as variáveis que indicam veracidade ou falsidade da informação e o seu âmbito de abrangência no contexto comunicacional que engloba indivíduos, grupos sociais, organizações e sociedades democráticas. (CANABARRO, 2018). Segundo o relatório produzido por encomenda do Conselho da Europa em Estrasburgo, a desordem informacional é um fenômeno mundial que se refere à poluição informacional na qual está inserida a sociedade e a utilização do termo fake news é insuficiente para capturar a complexidade desse fenômeno. A desordem informacional é constituída por três componentes, subdivididos em: três elementos (agente, mensagem e interpretante), três fases (criação, produção e distribuição) e três tipos (misinformation, disinformation e mal-information).

(Fonte: $<$ https://www.coe.int/en/web/freedom-expression/information-disorder $>$ ) Entretanto, neste trabalho utilizaremos o termo fake news para expressar a sua relação com a percepção-ação coletiva. Não é nosso objetivo, aqui, realizar um estudo pormenorizado dos três compenentes que constituem a desordem informacional. Isso será realizado em trabalhos posteriores.

${ }^{20}$ Neste trabalho, optamos por deixar as palavras misinformation, disinformation e mal-information na terminologia inglesa.

${ }^{21}$ Fonte:< https://g1.globo.com/fato-ou-fake/noticia/2018/12/05/e-fake-mensagem-que-diz-que-coco-quente-matacancer.ghtml $>$.

${ }^{22}$ Fonte: < https://g1.globo.com/fato-ou-fake/noticia/2018/12/11/e-fake-que-suco-de-quiabo-salva-cachorro-decinomose-e-parvovirose.ghtml $>$.

${ }^{23}$ Fonte: < https://g1.globo.com/fato-ou-fake/noticia/2018/11/27/e-fake-que-barrinha-colorida-em-caixa-de-leitequer-dizer-que-produto-venceu-mas-voltou-ao-mercado.ghtml $>$.

${ }^{24}$ Fontes:< https://www.mariellefranco.com.br/averdade > > https://congressoemfoco.uol.com.br/especial/noticias/cinco-mentiras-que-espalharam-sobre-marielle-equipe-da-exvereadora-lanca-site-contra-fake-news/ > .

${ }^{25}$ Fonte: < https://www.diariodocentrodomundo.com.br/professora-da-unb-e-sociologa-conservadora-cunhou-otermo-ursal-em-2001-como-chacota/ $>$.

${ }^{26}$ Fonte: $<\quad$ http://www.ebc.com.br/noticias/brasil/2014/05/quarto-agressor-da-mulher-linchada-em-guaruja-seentrega-a-policia $>$.

27Fonte: < https://g1.globo.com/fato-ou-fake/noticia/2018/07/30/video-mostra-multidao-de-venezuelanosComplexitas - Rev. Fil. Tem., Beeem, v. 3, n.1 , p. 130-160, jan./Jun. 2018-ISSN: 2525-4154 
invadindo-fronteira-com-o-brasil-fake.ghtml >.

${ }^{28}$ Fonte: $<$ https://link.estadao.com.br/noticias/cultura-digital,depois-das-fake-news-comecam-a-surgir-os-videosfalsos, $70002218025>$.

${ }^{29}$ Fonte: $<$ https://www1.folha.uol.com.br/ilustrissima/2018/04/com-avanco-tecnologico-fake-news-vao-entrar-emfase-nova-e-preocupante.shtml $>$.

${ }^{30}$ Fonte: $<$ http://complexitylabs.io/edge-of-chaos/ $>$

< https://www.youtube.com/watch?v=71n4GSM1jhw\&list=PLsJWgOB5mIMDRt8-DBLLVfh-XeKs2YAcg >.

${ }^{31}$ Informação verbal fornecida por Maria Eunice Quilici Gonzalez no $3^{\circ}$ Fórum de políticas públicas - ambiente e populações, em Marília, em julho de 2007.

${ }^{32}[\ldots]$ emergent properties of the dynamical interaction amongst elements at the micro-level. When OP's emerge, they enslave the behaviour of individual elements, producing new characteristics at the macroscopic scale. (HAKEN, 1988, p. 45).

${ }^{33}$ Fonte: $\quad$ https://theconversation.com/how-cambridge-analyticas-facebook-targeting-model-really-workedaccording-to-the-person-who-built-it-94078 >

34 Fonte: < https://www1.folha.uol.com.br/mercado/2018/03/entenda-o-escandalo-do-uso-de-dados-dofacebook.shtml $>$.

${ }^{35}$ Fonte: $\langle$ https://www.buzzfeednews.com/article/craigsilverman/partisan-fb-pages-analysis $>$.

${ }^{36}$ Pesquisa realizada pela Universidade Federal de Minas Gerais - UFMG também ressalta a relação entre polarização política e fake news. Utilizando dados coletados no Twitter referentes às eleições norte-americanas em 2016, a pesquisa mostrou que quanto mais politicamente extremista for o usuário das redes sociais, mais propenso estará a disseminação de fake news. (ALMEIDA, DONEDA, LEMOS, 2018).

${ }^{37}$ Como apontamos, disinformation é caracterizada como informação falsa criada com objetivo de prejudicar indivíduos, grupos sociais, organizações e Estados democráticos.

${ }^{38}$ Fonte: $<$ https://www.snopes.com/fact-check/pope-francis-donald-trump-endorsement/ $>$.

${ }^{39}$ Fonte: $<$ https://www.snopes.com/fact-check/hillary-clinton-has-parkinsons-disease/ $>$.

${ }^{40}$ Consideramos que as agências de checagem - fact-checking - responsáveis pela tarefa de apurar e controlar a veracidade de notícias que circulam nas mídias impressas e digitais, também devem ser criticamente avaliadas. É necessário investigar a origem de tais agências e como elas são mantidas em funcionamento, bem como a pretendida e apregoada neutralidade na apuração dos discursos que circulam nas mídias. É imprescindível que avaliemos as notícias, bem como as agências de checagens dessas notícias para não nos tornarmos reféns de grupos propensos a ditar o que é verdade e o que é mentira em diversos âmbitos na sociedade, de acordo com possíveis interesses específicos.

${ }^{41}$ It implies the complementarity of the animal and the environment. (GIBSON, 1986, p. 12).

${ }^{42}$ Fonte: $<$ https://g1.globo.com/politica/eleicoes/2018/eleicao-em-numeros/noticia/2018/10/28/percentual-de-votonulo-e-o-maior-desde-1989-soma-de-abstencoes-nulos-e-brancos-passa-de-30.ghtml > .

${ }^{43}$ Fontes:< https://www.nbcnews.com/politics/2016-election/trump-lewandowski-they-re-destroying-very-goodperson-n548036 > < https://brasil.elpais.com/brasil/2016/04/01/internacional/1459535583_669754.html >.

${ }^{44}$ Fontes: $<$ https://g1.globo.com/rj/rio-de-janeiro/eleicoes/2018/noticia/2018/10/18/jair-bolsonaro-afirma-que-naovai-a-debates-no-segundo-turno.ghtml $><$ https://www.cartacapital.com.br/politica/bolsonaro-nao-vai-participarde-debates-no-segundo-turno/ $>$.

${ }^{45}$ Fontes: < https://www.uol/eleicoes/especiais/votar-nulo-anular-voto-em-branco-eleicoes-2018-htm\#nao-temuma-pessoa-que-mereca-o-nosso-voto $>$.

${ }^{46}$ Fonte: < https://www1.folha.uol.com.br/poder/2018/10/entre-brigas-bolhas-e-boatos-medo-e-raiva-dominameleitores.shtml $>$.

${ }^{47}$ Fonte: $<$ https://www.bbc.com/portuguese/brasil-42243930 >.

${ }^{48}$ Let us explain what we mean by this phrase embodied action. By using the term embodied we mean to highlight two points: first, that cognition depends upon the kinds of experience that come from having a body with various sensorimotor capacities, and second, that these individual sensorimotor capacities are themselves embedded in a more encompassing biological, psychological, and cultural context. (VARELA. et. al. 1991, p. 172-173).

${ }^{49}$ Apesar da abordagem proposta por Varela et al. (1991) ser anti-representacionista tal como a perspectiva elaborada por Gibson (1986) acerca da percepção, ela diverge da proposta gibsoniana no que concerne às concepções de reciprocidade organismo-ambiente e de percepção direta. Como ressaltamos, não é nosso objetivo, neste trabalho, esmiuçar as diferenças entre as perspectivas varelianas e gibsonianas acerca da percepção.

${ }^{50}[\ldots]$ it could be said that an affordance is what the environment means to a perceiver. [...] To detect affordances is, quite simply, to detect meaning. (MICHAELS, CARELLO, 1981, p. 42, tradução nossa).

${ }^{51}$ From an ecological point of view, intentions are not causes of action, but patterns of organization of action; they are not mental as opposed to physical, but are instead embodied in the kinds of performances most likely found in cognitively capable creatures. (Reed, 1993, p. 62).

Complexitas - Rev. Fil. Tem., Belém, v. 3, n.1, p. 130-160, jan./jun. 2018 - ISSN: 2525-4154 
${ }^{52}[\ldots]$ autonomy is characterized here not in terms of the absence of restrictions, but rather in accordance with consensual agreements established amongst social agents for the benefit of all. (GONZALEZ et al. 201, p.163).

${ }^{53}$ Fontes:< https://www.nexojornal.com.br/expresso/2017/07/03/Trump-\%E2\%80\%98fake-news\%E2\%80\%99-e-aguerra-declarada-contra-a-imprensa $><$ https://g1.globo.com/mundo/noticia/2018/08/16/trump-rebate-campanhade-jornais-e-acusa-imprensa-de-publicar-mentiras-honestidade-vencera.ghtml

https://noticias.bol.uol.com.br/ultimas-noticias/internacional/2018/10/17/apos-entrevista-trump-critica-agenciaassociated-press-fake-news.htm $>\langle$ https://www.bbc.com/portuguese/internacional-38060745 $>$.

${ }^{54}$ Fontes:< https://www1.folha.uol.com.br/poder/2018/10/folha-e-a-maior-fake-news-do-brasil-diz-bolsonaro-a$\underline{\text { manifestantes.shtml }}$

https://www1.folha.uol.com.br/poder/2018/10/folha-e-a-maior-fake-news-do-brasil-diz-bolsonaro-amanifestantes.shtml $><$ https://noticias.uol.com.br/politica/eleicoes/2018/noticias/2018/10/26/bolsonaro-haddadvideo-fake-news.htm $><$ https://extra.globo.com/noticias/brasil/bolsonaro-declara-guerra-midia-fake-news-causaapreensao-nas-redacoes-23210706.html $>$.

${ }^{55}$ Fonte: $<$ https://theintercept.com/2017/12/12/depois-do-maior-vexame-dos-ultimos-tempos-midia-dos-eua-relutaem-ser-transparente/ $><$ https://www.diariodocentrodomundo.com.br/essencial/fake-news-bolsonaro-naoautorizou-execucao-de-divida-da-tv-globo/ $><$ https://www.brasil247.com/pt/colunistas/esmaelmorais/331723/Secriminalizar-as-fake-news-dan\%C3\%A7am-Globo-Veja-Estad\%C3\%A3o-Folha-et-caterva.htm

<https://www.pragmatismopolitico.com.br/2018/02/estadao-publica-fake-news-incriminar-lula.html

$\langle$ https://www.diariodocentrodomundo.com.br/essencial/fake-news-herdeiro-do-estadao-diz-que-filho-de-ditador-

africano-veio-trazer-dinheiro-de-campanha-para-haddad/ $>$.

\section{REFERÊNCIAS BIBLIOGRÁFICAS}

ALMEIDA, V.; DONEDA, D.; LEMOS, R. Com avanço tecnológico, fake news vão entrar em fase nova $e$ preocupante. Folha de São Paulo, São Paulo, 8 de abr. 2018. Disponível em: $<$ https://www1.folha.uol.com.br/ilustris sima/2018/04/com-avanco-tecnologicofake-news-vao-entrar-em-fase-nova-epreocupante.shtml >. Acesso em: 08 de jan. 2019.

ANGIOLILLO, F. Entre brigas, bolhas $e$ boatos, medo e raiva dominam eleitores. Folha de São Paulo, São Paulo, 28 de out. 2018. Disponível em: $<$ https://www1.folha.uol.com.br/pod er/2018/10/entre-brigas-bolhas-e-

boatos-medo-e-raiva-dominameleitores.shtml >. Acesso em: 08 de jan. 2019.

AZEVEDO, A. L.; TRIGUEIRO, A.; MARTINS, M. A. Jair Bolsonaro afirma que não vai a debates no segundo turno. G1, Rio de Janeiro, 18 de out. 2018. Disponível em:< https://g1.globo.com/rj/rio-dejaneiro/eleicoes/2018/noticia/2018/10/1 8/jair-bolsonaro-afirma-que-nao-vai-a- debates-no-segundo-turno.ghtml $>$. Acesso em: 11 de jan. 2019.

BOADLE, A.; SLATTERY, G. Bolsonaro declara guerra à mídia 'fake news' e causa apreensão nas redações. (traduzido por EXTRA). REUTERS, Brasília e São Paulo, 4 de nov. 2018. Disponível $\mathrm{em}:<$ https://extra.globo.com/noticias/brasil/b olsonaro-declara-guerra-midia-fakenews-causa-apreensao-nas-redacoes23210706.html >. Acesso em: 12 de jan. 2019.

BOL NOTÍCIAS. Após entrevista, Trum critica agência "Associated Press": "Fake news". BOL Notícias, 17 de out. 2018. Disponível em:< https://noticias.bol.uol.com.br/ultimasnoticias/internacional/2018/10/17/aposentrevista-trump-critica-agenciaassociated-press-fake-news.htm >. Acesso em: 12 de jan. 2019.

CANABARRO, D. R. Para além das "fake news": os componentes da chamada "desordem informacional". Observatório da internet no Brasil, 06 de set. 2018. Disponível em:< 
https://observatoriodainternet.br/post/pa ra-alem-das-fake-news-oscomponentes-da-chamada-desordeminformacional >. Acesso em: 09 de jan. 2019.

CARELlO, C.; MICHAELS, C. F. Direct perception. USA: Prentice-Hall, Englewood cliffs, 1981.

CARTA CAPITAL. Bolsonaro afirma que não participará de debates no segundo turno. São Paulo, 18 de out. 2018. Disponível em: < https://www.cartacapital.com.br/politica /bolsonaro-nao-vai-participar-dedebates-no-segundo-turno/ >. Acesso em: 11 de jan. 2019.

COMPLEXITY THEORY COURSE INTRODUCTION. Complexity labs. 2015. Disponível em: <https://www.youtube.com/watch?v $=71 \mathrm{n}$ 4GSM1jhw\&list=PLsJWgOB5mI MDRt8-DBLLVfh-XeKs2YAcg >. Acesso em: 11 de set. 2018.

COSTA, J. L.; SILVA, A. R. B.; MURALOLLI, P. L. Aplicação do big data nas áreas de saúde, esporte, pecuária e minério. In: Perspectivas em Ciências Tecnológicas, 2017, p. 9-28. Disponível em: <http://www.fatece.edu.br/arquivos/arq uivos\%20revistas/perspectiva/volume6/ 1.pdf >. Acesso em: 10 de jan. 2019.

DCM. Fake news: Bolsonaro não autorizou execução de dívida da TV Globo. O Essencial, 11 de jan. 2019. Disponível

em: $<$ https://www.diariodocentrodomun do.com.br/essencial/fake-newsbolsonaro-nao-autorizou-execucao-dedivida-da-tv-globo/ >. Acesso em: 13 de jan. 2019.

DCM. Fake news: herdeiro do Estadão diz que filho de ditador africano "veio trazer dinheiro de campanha para Haddad. O Essencial, 16 de set. 2018. Disponível https://www.diariodocentrodomundo.co $\underline{\mathrm{m} . \mathrm{br} / \mathrm{essencial} / \mathrm{fake} \text {-news-herdeiro-do- }}$ estadao-diz-que-filho-de-ditadorafricano-veio-trazer-dinheiro-decampanha-para-haddad/ >. Acesso em: 13 de jan. 2019.

DEBORD, G. A sociedade do espetáculo. 2003. Disponível em: < https://www.marxists.org/portugues/deb ord/1967/11/sociedade.pdf $>$. Acesso em: 30 de jul. 2018.

DOMINGOS, R. É \#FAKE mensagem que diz que coco quente mata câncer. G1, Rio de Janeiro, RJ, 05 de dez. 2018. Disponível

em: $<$ https://g1.globo.com/fato-oufake/noticia/2018/12/05/e-fakemensagem-que-diz-que-coco-quentemata-cancer.ghtml >. Acesso em: 09 de jan. 2019.

EDGE OF CHAOS. Complexity labs. Disponível em:< http://complexitylabs.io/edge-ofchaos/>. Acesso em: 11 de set. 2018.

EMERY, D. Did a Physician Confirm Hillary Clinton Has Parkinson's Disease? Snopes, EUA, 09 de set. 2016. Disponível em:< https://www.snopes.com/factcheck/hillary-clinton-has-parkinsonsdisease/ >. Acesso em: 10 de set. 2018.

ESTEVES, R.; GRANDIN, F.; OLIVEIRA, L. Percentual de voto nulo é o maior desde 1989; soma de abstenções, nulos e brancos passa de $30 \%$. G1, Rio de Janeiro, 28 de out. 2018. Disponível em: <https://g1.globo.com/politica/eleicoes/ 2018/eleicao-emnumeros/noticia/2018/10/28/percentualde-voto-nulo-e-o-maior-desde-1989soma-de-abstencoes-nulos-e-brancospassa-de-30.ghtml >. Acesso em: 11 de jan. 2019.

EVON, D. Pope Francis Shocks World, Endorses Donald Trump for President. 
Snopes, EUA, 10 de jul. 2016. Disponível em: < https://www.snopes.com/factcheck/pope-francis-donald-trumpendorsement/ >. Acesso em: 10 de set. 2018.

FACEBOOK. Cookies $e$ outras tecnologias de armazenamento. 2018. Disponível em <https://www.facebook.com/policies/co okies/ >. Acesso em: 10 de jan. 2019.

___ Política de Dados, 2018. Disponível em:< https://www.facebook.com/about/privac y/update $>$. Acesso em: 10 de jan. 2019.

FELLET, G. Como imprensa dos EUA pode ter ajudado a eleger Trump, mesmo com cobertura negativa. BBC News, 23 de nov. 2016. Disponível em: $<$

https://www.bbc.com/portuguese/intern acional-38060745 >. Acesso em: $12 \mathrm{de}$ jan. 2019.

G1. É \#FAKE que suco de quiabo salva cachorro de cinomose e parvovirose. G1, Rio de Janeiro, Rj, 11 de dez. 2018. Disponível em: $<$ https://g1.globo.com/fato-oufake/noticia/2018/12/11/e-fake-quesuco-de-quiabo-salva-cachorro-decinomose-e-parvovirose.ghtml>. Acesso em: 09 de jan. 2019.

Trump rebate campanha de jornais e acusa imprensa de publicar mentiras: 'Honestidade vencerá!' G1, Rio de Janeiro, 16 de ago. 2018. Disponível em: < https://g1.globo.com/mundo/noticia/201 8/08/16/trump-rebate-campanha-dejornais-e-acusa-imprensa-de-publicarmentiras-honestidade-vencera.ghtml >. Acesso em: 12 de jan. 2019.

GIBSON, J. J. The Ecological Approach to visual perception. New Jersey: Lawrence Earlbaum Associates, Inc. 1986.
GIBSON, E. J. Ontogenesis of the perceived self. In: The perceived self: ecological and interpersonal sources of self-knowledge. Cambridge: Cambridge University Press, 1993, p. 25-42.

GREENWALD, G. Depois do maior vexame dos últimos tempos, mídia dos EUA reluta em ser transparente. The Intercept Brasil, 12 de dez. 2017. Disponível em:< https://theintercept.com/2017/12/12/dep ois-do-maior-vexame-dos-ultimostempos-midia-dos-eua-reluta-em-sertransparente/ $>$. Acesso em: 13 de jan. 2019.

GONZALEZ, J. A. Q.; et al. Complexity and information technologies: an ethical inquiry into human autonomous action. In: Sciente e Studia. São Paulo, 2014, p. 161-179.

GRAGNANI, J. Como 'comportamento de manada' permite manipulação da opinião pública por fakes. BBC NEWS BRASIL, 9 de dez. 2017. Disponível em:<

https://www.bbc.com/portuguese/brasil$\underline{42243930}$ >. Acesso em: 11 d jan. 2019.

HAKEN, H. Information and selforganization: a macroscopic approach to complex systems. Berlin: SpringerVerlag, 1988.

HINDMAN, M. How Cambridge Analytica's Facebook targeting model really worked according to the person who built it. The Conversation, EUA, 30 de mar. 2018. Disponível $\mathrm{em}:<$ https://theconversation.com/howcambridge-analyticas-facebooktargeting-model-really-workedaccording-to-the-person-who-built-it94078 >. Acesso em: 10 de set. 2018.

IANDOLI, R. Trump, "fake news" e a guerra declarada contra a imprensa. Nexo, 3 de jul. 2017. Disponível em: <https://www.nexojornal.com.br/expres 
so/2017/07/03/Trump-

\%E2\%80\%98fake-news\%E2\%80\%99e-a-guerra-declarada-contra-a-imprensa >. Acesso em: 12 de jan. 2019.

ILIADIS, A.; RUSSO, F. Critical data studies: an introduction. In: Big Data \& Society. 2016. Disponível em:< https://journals.sagepub.com/doi/pdf/10 $\underline{.1177 / 2053951716674238}>$. Acesso em: 08 de set. 2018.

INTEL. Guia de Planejamento: Introdução à Big Data. Intel Corporation, 2014. Disponível em:< https://www.intel.com.br/content/dam/ www/public/lar/br/pt/documents/article s/e7-big-data-planning-guide-webreadypor.pdf >. Acesso em: 10 de jan. 2019.

JAIN， P.; GYANCHANDANI， M.; KHARE, N. Big data privacy: a technological perspective and review. In: Jain et al. J Big Data, 2016, p. 2-25.

JULIÃO, L.G. É \#FAKE que vídeo mostra multidão de venezuelanos 'invadindo' fronteira com o Brasil. G1, Rio de Janeiro, RJ, 30 de jul. 2018. Disponível em:< https://g1.globo.com/fato-oufake/noticia/2018/07/30/video-mostramultidao-de-venezuelanos-invadindofronteira-com-o-brasil-fake.ghtml >. Acesso em: 09 de jan. 2019.

LARGE, D. N. Ecological philosophy. Web Version, 2003. Disponível em:< http://www.newphilsoc.org.uk/Ecologic al/DavidLarge.PDF >. Acesso em: 10 dez. 2007.

MARQUES, J. Folha é a maior fake news do Brasil, diz Bolsonaro a manifestantes. Folha de São Paulo, São Paulo, 21 de out. 2018. Disponível em: <https://www1.folha.uol.com.br/poder/ 2018/10/folha-e-a-maior-fake-news-dobrasil-diz-bolsonaro-amanifestantes.shtml >. Acesso em: 12 de jan. 2019.
MARTÍ, S. Entenda o escândalo do uso de dados do Facebook. Folha de São Paulo, São Paulo, 22 de mar. 2018. Disponível em:< https://www1.folha.uol.com.br/mercado /2018/03/entenda-o-escandalo-do-usode-dados-do-facebook.shtml >. Acesso em: 7 de jan. 2019.

MAYER-SCHÖNBERGER, $\quad \mathrm{V}$;; CUKIER, K. Big data: a revolution that will transform how we live, work and think. Boston, New York: Eamon Dolan book / Houghton Mifflin Harcourt. 2013.

MEGLIACCI, P. Não acredite cegamente em algoritmos porque até eles erram. Folha de São Paulo, São Paulo, 11 de set. 2018. Disponível em:<https://www1.folha.uol.com.br/tec/ 2018/09/nao-acredite-cegamente-emalgoritmos-porque-ate-eles-erram.shtml >. Acesso em: 09 de jan. 2019.

MONGE, Y. O misógino Donald Trump. El País, São Paulo, 2 de abr. 2016.

Disponível em: $<$ https://brasil.elpais.com/brasil/201 6/04/01/internacional/1459535583 669 754.html >. Acesso em: 11 de jan. 2019.

MORAIS, E. Se criminalizar as fake news, dançam Globo, Veja, Estadão, Folha, et caterva. Brasil 247, 12 de dez. 2017. Disponível em: < https://www.brasil247.com/pt/colunista s/esmaelmorais/331723/Secriminalizar-as-fake-newsdan\%C3\% A7am-Globo-VejaEstad\%C3\%A3o-Folha-et-caterva.htm >. Acesso em: 13 de jan. 2019.

MOREIRA, M. Quarto agressor da mulher linchada em Guarujá se entrega à polícia. EBC, Brasília, 09 de maio, 2014.

Disponível em: $<$ http://www.ebc.com.br/noticias/br asil/2014/05/quarto-agressor-damulher-linchada-em-guaruja-seentrega-a-policia>. Acesso em: $10 \mathrm{de}$ 
set. 2018 .

MORIN, E. Introdução ao pensamento complexo. Lisboa: Instituto Piaget. 1995.

Ciência com consciência. Rio de Janeiro: Bertrand Brasil. 2005.

MORONI, J. Cognição incorporada e sua compatibilidade com o realismo ecológico gibsoniano. In: Anais do seminário dos estudantes de pósgraduação em filosofia da UFSCar, 2014, p. 227-254. Disponível em:< http://www.ufscar.br/ semppgfil/wpcontent/uploads/2012/05/23-JulianaMoroni.pdf >. Acesso em: $11 \mathrm{de}$ jan. 2019.

MOURA, D.; RAMOS, P. Não voto em ninguém. UOL, 6 de out. 2018. Disponível

em: $<$ https://www.uol/eleicoes/especiais /votar-nulo-anular-voto-em-brancoeleicoes-2018-.htm> Acesso em: 11 de jan. 2019.

NOGUEIRA, K. Professora da UnB e socióloga conservadora cunhou o termo URSAL em 2001 como chacota. DCM Diário do Centro do Mundo, São Paulo, 11 de ago. 2016. Disponível em: $<$ https://www.diariodocentrodomun do.com.br/professora-da-unb-esociologa-conservadora-cunhou-otermo-ursal-em-2001-como-chacota/ >. Acesso em: 10 de set. 2018.

PACHARIE, E. How does it feel to act together? In: Phenomenology and the Cognitive Sciences. Springer, V. 13, 2014, p. 25-46.

The sense of control e the sense of agency. In: Psyche, V. 13, 2007, p. 130. Disponível em: < http://journalpsyche.org/files/0xab10.pd f >. Acesso em: 07 de jan. 2019.

PRAGMATISMO POLÍTICO. Estadão publica fake news para incriminar Lula.
Pragamatismo Político, 26 de fev. 2018. Disponível

em: $<$ https://www.pragmatismopolitico. com.br/2018/02/estadao-publica-fakenews-incriminar-lula.html > Acesso em: 13 de jan. 2019.

PRESS, G. Top 10 Hot Big Data Technologies. Forbes USA, 14 de mar. 2016. Disponível em:<https://www.forbes.com/sites/gilpr ess/2016/03/14/top-10-hot-big-datatechnologies/\#7fb3842e65d7 >. Acesso em: 10 de jan. 2019.

REED, E. S. The intention to use a specific affordance: a framework for psychology. In R. Wozniak, \& K. Fisscher (Eds.), Development in context: Acting and thinking in specific environment. Hillsdale, NJ: Lawrence Erlbaum Associates, 1993, p. 45-75.

. Encountering the world. New York: Oxford University Press. 1996.

RONCOLATO, M. O que diz a nova lei de proteção de dados da Europa. E o efeito no Brasil. Nexo Jornal, São Paulo, 25 de Maio, 2018. Disponível em:

<https://www.nexojornal.com.br/expres so/2018/05/25/O-que-diz-a-nova-lei-deprote $\% \mathrm{C} 3 \% \mathrm{~A} 7 \% \mathrm{C} 3 \% \mathrm{~A} 30-$ de-dadosda-Europa.-E-o-efeito-no-Brasil >. Acesso em: 20 de set. 2018.

ROOSE, K. Depois das 'fake news', começam a surgir os vídeos falsos. (Traduzido por Claudia Bozzo). Estadão, São Paulo, 8 de mar. 2018. Disponível em: $<$ https://link.estadao.com.br/noticias /cultura-digital,depois-das-fake-newscomecam-a-surgir-os-videos-

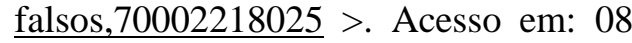
de jan. 2019.

SANTOS, G. Fake news: 5 mentiras que espalharam sobre Marielle. Congresso em Foco, Brasília, 19 de mar. 2018. Disponível em:< 
https://congressoemfoco.uol.com.br/esp ecial/noticias/cinco-mentiras-queespalharam-sobre-marielle-equipe-daex-vereadora-lanca-site-contra-fakenews/ >. Acesso em: 10 de set. 2018.

SILVERMAN, C. et al. Hyperpartisan Facebook Pages Are Publishing False And Misleading Information At An Alarming Rate. BuzzFeed News, EUA, 20 de out. 2016. Disponível em: $<$ https://www.buzzfeednews.com/ar ticle/craigsilverman/partisan-fb-pagesanalysis>. Acesso em: 7 de jan. 2019.

UOL. O que são cookies e como eles podem me prejudicar? UOL Segurança digital, 26 de jun. 2013. Disponível em: $<$

https://seguranca.uol.com.br/antivirus/d icas/curiosidades/o-que-sao-cookies-ecomo-eles-podem-meprejudicar.html\#rmcl >. Acesso em: 10 de jan. 2019.

- Bolsonaro cita informações $\overline{\text { falsas }}$ ao acusar PT de espalhar fake news. UOL, 26 de out. 2918. Disponível em:

<https://noticias.uol.com.br/politica/elei coes/2018/noticias/2018/10/26/bolsonar o-haddad-video-fake-news.htm >. Acesso em: 12 de jan. 2019.

VALENTE, J. Lei de Proteção de Dados trará impactos a pessoas, empresas e governos. Agência Brasil EBC, Brasília, 18 de ago. 2018. Disponível em: <http://agenciabrasil.ebc.com.br/geral/n oticia/2018-08/lei-de-protecao-dedados-trara-impactos-pessoasempresas-e-governos>. Acesso em: 7 de jan. 2019.

VARELA, F. ; THOMPSON, E. ; $\mathrm{ROSCH}$, E. The embodied mind. Cambridge, MA: MIT-Press, 1991.

VELASCO, C. É \#FAKE que 'barrinha colorida' em caixa de leite indique produto vencido que voltou ao mercado. G1, Rio de Janeiro, RJ, 27 de nov. 2018.2 Disponível em: $<$ https://g1.globo.com/fato-oufake/noticia/2018/11/27/e-fake-quebarrinha-colorida-em-caixa-de-leitequer-dizer-que-produto-venceu-masvoltou-ao-mercado.ghtml >. Acesso em: 09 de jan. 2019.

VILELA, P. R. Empresa que vazar dados de clientes pode ser multada em até $R \$ 50$ milhões. Brasil de Fato, São Paulo, 14 de jul. 2018. Disponível em: $<$ https://www.brasildefato.com.br/2 018/07/14/empresa-que-vazar-dadosde-clientes-pode-ser-multada-em-aterdollar-50-milhoes/ >. Acesso em: $10 \mathrm{de}$ set. 2018.

VITALI, A. Trump Advocates Abortion Ban, Walks Back 'Punishment' for Women Remark. NBC NEWS, 30 de mar. 2016. Disponível em: < https://www.nbcnews.com/politics/2016 -election/trump-lewandowski-they-redestroying-very-good-person-n548036 >. Acesso em: 11 de jan. 2019.

WARDLE, C.; DERAKHSHAN, $\mathrm{H}$. Information Disorder: Toward an interdisciplinary framework for research and policymaking. Strasbourg: the Council of Europe, 2017. Disponível em: $<$ https://rm.coe.int/informationdisorder-toward-an-interdisciplinaryframework-for-researc/168076277c $>$. Acesso em: 09 de jan. 2019.

WITHAGEN, R.; et al. Affordances can invite behavior: reconsidering the relationship betweeen affordances and agency. In: New Ideas in Psychology, Elsevier, 2012, p. 250-258. Disponível em:

http://www.academia.edu/1209074/Aff ordances can invite behavior Reconsi dering the relationship_between_affor dances_and_agency $>$. Acesso em: 24 de set. 2015.

ZHAO, Z.; et al. Fake news propagate 
differently from real news even at early stages of spreading. 2018. (Submitted on 9 Mar 2018 (v1), last revised 12 Mar 2018 (this version, v2)). Disponível em:<

https://arxiv.org/ftp/arxiv/papers/1803/1 803.03443.pdf $>$. Acesso em: 21 de jul. 2018.

MORORI, J. Possíveis Impactos de Fake News na Percepção-Ação Coletiva. Complexitas - Rev. Fil. Tem. Belém, v. 3, n. 1, p. 130-160, jan./jun. 2018. Disponível em:< http://www.periodicos.ufpa.br/index.php/complexitas/article/view/6625>. Acesso em: 20 de fevereiro de 2019. 